\title{
Paraplegia Following Obstetric Spinal Anesthesia: A Case Report
}

\author{
Jedsadayoot Sakaroonchai*, Arpakorn Kunawudhi and Preeyaphan Arunakul \\ Department of Anesthesiology, Thammasat University, Thailand \\ *Corresponding author: Jedsadayoot Sakaroonchai, Department of Anesthesiology, Thammasat University, Thailand
}

\begin{tabular}{|c|c|}
\hline ARTICLE INFO & ABSTRACT \\
\hline Received: 蔧 June 24, 2019 & Neurologic complication following spinal anesthesia is rare, but it can lead to seri- \\
\hline Published: 幽 July 02, 2019 & $\begin{array}{l}\text { ous neurologic sequelae. Direct needle injury to the cord, epidural hematoma, epidural } \\
\text { abscess, spinal cord infarction, cauda equina syndrome or compression from extradural }\end{array}$ \\
\hline $\begin{array}{l}\text { Citation: Jedsadayoot S, Arpakorn K, } \\
\text { Preeyaphan A. Paraplegia Following Ob- } \\
\text { stetric Spinal Anesthesia: A Case Report. }\end{array}$ & $\begin{array}{l}\text { mass have been documented as causes of paraplegia. We report a patient who developed } \\
\text { paraplegia following an uneventful spinal anesthesia for caesarean section and under- } \\
\text { went emergency surgery for a previously undiagnosed thoracic intradural extramedul- } \\
\text { lary tumor which was thought to be the cause of neurologic complication. }\end{array}$ \\
\hline
\end{tabular}
BJSTR. MS.ID.003280.
Keywords: Paraplegia; Spinal anesthesia; Obstetric; Spinal tumor; Intradural extramedullary tumor; Neurologic complication

\section{Introduction}

Neurological deficit is an uncommon but a catastrophic complication after spinal anesthesia. Neurologic complication as vertebral canal hematoma, epidural abscess, cauda equina syndrome, arachnoiditis, trauma, transient neurological syndrome following obstetric central neuraxial anesthesia have been documented [1]. We report the case of obstetric patient who developed paraplegia after spinal anesthesia.

\section{Case Report}

A 37 years old female with 38 weeks of gestation was planned for cesarean section due to breech presentation. The patient was healthy and was not taking any medication. The vital signs, general physical examinations and routine investigations were unremarkable. Spinal anesthesia was performed with aseptic technique at the L3-4 interspace in paramedian approach using a 27G Quincke spinal needle in a single attempt. After confirming entry by free flow of clear cerebrospinal fluid (CSF), 10mg of $0.5 \%$ hyperbaric bupivacaine with $0.2 \mathrm{mg}$ of morphine was given in a total volume of $2.2 \mathrm{ml}$. The patient then developed a sensory blockade up to T4 dermatomal level. Intraoperative course was uneventful and all the vital parameters were maintained within normal range. Eight hours after the surgery, the patient still had lower extremities weakness. She had no fever or back pain. Neurologic examinations revealed loss of sensation below L1 dermatome and decreased motor strength of both lower extremities, according to Medical Research Council grading, quantified as followed: bilateral hip flexion II/V; bilateral knee extension II/V; bilateral foot dorsiflexion IV/V; and bilateral plantar flexion IV/V. Both lower extremities showed increased muscle tone and prepatellar reflexes. Rectal and sphincter tone were decreased. Besides that, the patient also mentioned that 2 weeks prior to admission she started feeling numbness in legs but did not recognize that as a problem. An urgent magnetic resonance imaging (MRI) of thoracolumbar spine shows dural-based mass at posterior wall of thecal sac at the T10-T11 vertebral level with spinal cord compression (Figure 1). Microscopic decompressive laminotomy with tumor removal was operated on the next day. After surgery, the patient's symptoms began to resolve, and she was able to walk with assistance. Pathological study of the tissue showing atypical meningioma (WHO grade II) was reported. Four months later, she was fully recovered and repeated MRI thoracolumbar spine showed no residual tumor (Figure 2). 


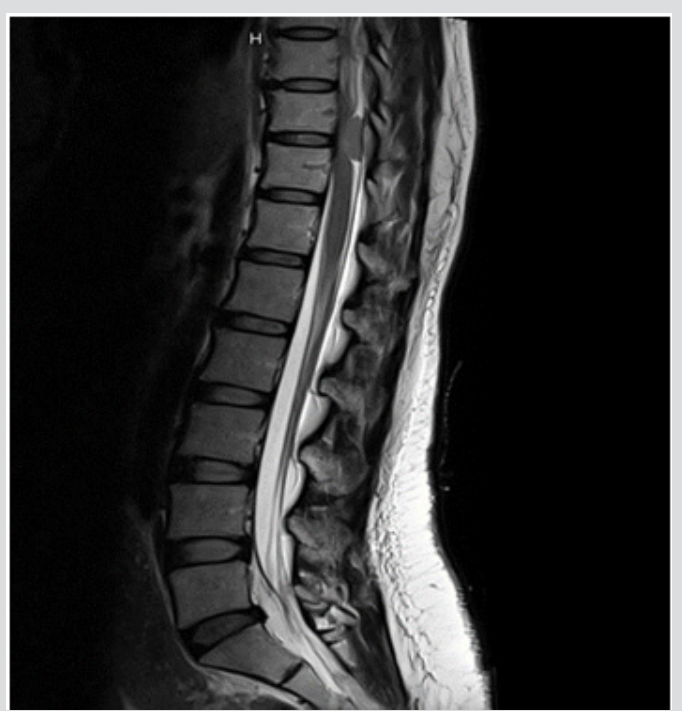

Figure 1: Magnetic resonance imaging of spine showing dural-based mass at posterior wall of thecal sac at the T10-T11 vertebral, measured $0.9 \times 1.0 \times 2.0 \mathrm{~cm}$. in dimension. Mass effect with spinal stenosis and spinal cord compression.

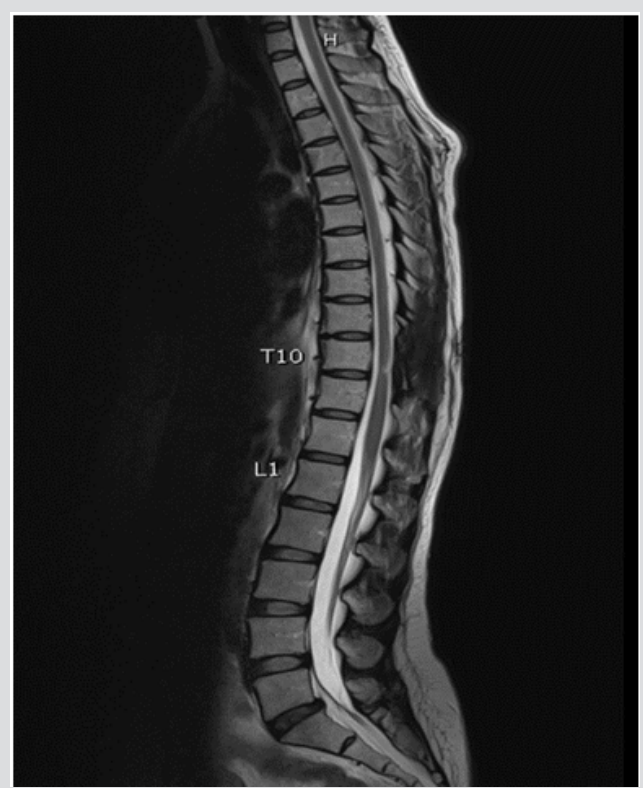

Figure 2: Magnetic resonance imaging of spine showing post tumor removal at $\mathrm{T} 10-11$ with no residual or recurrent tumor.

\section{Discussion}

Though extremely rare, spinal anesthesia has been shown to facilitate the manifestation of paraplegia secondary to spinal cord compression due to previously undiagnosed spinal cord tumor. The exact incidence of neurological complication following neuraxial anesthesia is difficult to determine but has been quoted to be between 0.3 and 1.2 per 100,000 [2]. Direct needle injury to the cord, epidural hematoma, epidural abscess, spinal cord infarction, cauda equina syndrome or compression from extradural mass have been documented as causes of paraplegia [3].

In this report, acute paraplegia after spinal anesthesia occurred in the obstetric patient with previously undiagnosed spinal intradural extramedullary tumor. Spinal tumor can cause acute neurological deterioration following lumbar puncture through many mechanisms. Spinal coning is one of the mechanisms leading to the neurologic complication. Hollis et al. reported that spinal coning results from sudden change of pressure differences above and below the level of block, which may cause impaction of the tumor against the cord and neurological deterioration [4]. Another mechanism is the loss of CSF from the lumbar puncture site may cause epidural venous engorgement that compromising venous drainage from the spinal cord below the tumor mass [4]. Nicholson et al. mentioned the possible neurological deterioration after spinal anesthesia in the presence of previously undiagnosed spinal tumors is neurologic toxicity of local anesthetics. The injected anesthetic agent cannot be diluted appropriately and accumulation of drug due to impaired flow of cerebrospinal fluid caused by the lesion [5]. These mechanisms may explain worsening in intradural extramedullary tumors.

In our patient, she started feeling numbness in both legs since before surgery and developed paraplegia after spinal anesthesia. A complete history and a careful neurologic examination before spinal or epidural anesthesia is essential in the prevention of serious neurologic complication. If neurologic deficits following spinal or epidural anesthesia did not recover within hours, MRI of the spine should be done immediately to enable early detection and appropriate management to save the patient from the ensuing devastating consequences.

\section{References}

1. Alastair D, Santosh P (2016) Neurological complications in obstetric regional anesthetic practice. Journal of Obstetric Anaesthesia and Critical Care 6(1): 3-10.

2. Rodgers A, Walker N, Schug S, McKee A, Kehlet H, et al. (2000) Reduction of postoperative mortality and morbidity with epidural or spinal anaesthesia. BMJ 321(7275): 1493.

3. Andrés L, Julián BL, Juan F (2013) Paraplegia after epidural anaesthesia. Pract Neurol 13(3):188-191.

4. Hollis PH, Malis LI, Zapulla PA (1986) Neurological deterioration after lumbar puncture below complete spinal subarachnoid block. J Neurosurg 64(2): 253-256.

5. Nicholson MJ, Everson UH (1946) Neurologic complications of spinal anesthesia. J Am Med Assoc 132(12): 679-685. 


\section{ISSN: 2574-1241}

DOI: 10.26717/BJSTR.2019.19.003280

Jedsadayoot Sakaroonchai. Biomed J Sci \& Tech Res

(c) (i) This work is licensed under Creative

Submission Link: https://biomedres.us/submit-manuscript.php

$\begin{array}{ll}\text { BIOMEDICAL } & \text { Assets of Publishing with us } \\ \text { RESEARCHES } & \text { - Global archiving of articles } \\ \text { - Immediate, unrestricted online access } \\ \text { - Rigorous Peer Review Process }\end{array}$

